\title{
Psigida walkeri (Grote) e seus estágios imaturos (Lepidoptera, Saturniidae, Ceratocampinae)
}

\author{
Eurides Furtado ${ }^{1}$
}

\begin{abstract}
Psigida walkeri (Grote) and its immature stages. (Lepidoptera, Saturniidae, Ceratocampinae). The biology and immature stages of Psigida walkeri (Grote) are described for the first time. Development is rapid with only 35 days from egg to adult. The larva feed on Calliandra parviflora Benth. (Leguminosae-Mimosoideae), its natural host plant. Egg, larval instars, pupa and adults are illustrated in color. KEY WORDS. Brazil, Ceratocampinae, Immature stages, Lepidoptera, Saturniidae
\end{abstract}

OiticicA-FiLHo (1959) ao criar o gênero Psigida não esclareceu em definitivo a confusão de nomenclatura da espécie tipo do novo gênero, Anisota walkeri Grote, 1867, mais conhecida então como Adelocephala apollinarei Dognin, 1919, e sugeriu um estudo mais aprofundado e a designação de um lectótipo para a espécie. LEMAIRE (1988) ao designar o neótipo para a espécie de Grote, pôs fím à confusão de nomenclatura, e apollinarei entrou definitivamente na sinonímia.

\section{MORFOLOGIA}

\section{Ovo (Fig. 1)}

Elipsóide, com as duas faces achatadas e orladas de preto; verde-claro brilhante; cório de aspecto coriáceo, micro-sulcado. Mede, 2,0 mm no maior eixo e 1,6 mm no menor. Período embrionário, seis a sete dias.

\section{Larva}

Primeiro ínstar (Fig. 2). Cabeça: marrom-clara brilhante. Corpo: cada segmento torácico com dois pares de scoli escuros dispostos em cada lado subdorsal; os do protórax curtos, com as ramificações minúsculas, base verrugosa marrom-clara brilhante; os meso-e os metatorácicos são maiores, com ramificações espiniformes, haste com a porção apical amassada, triangular, bifurcada. Abdome com quatro series de scoli escuros, inclinados para a frente: a primeira subespiracular, hastes mais curtas; a segunda supraespiracular; a terceira e a quarta subdorsais. Todos os scoli são espiniformes com pequenas ramificações. Grosso scolus dorsal em A8, base marrom-clara brilhante, haste escura com ramificações espiniformes e o ápice bifurcado. Placa supranal amarelada, com chalazae dorsais e laterais, escuras. Pernas torácicas e abdominais, creme. Tegumento verde-oliváceo, amarelado na base dos scoli subespiraculares. Comprimento ao emergir, $5,0 \mathrm{~mm}$; no final do ínstar, 7,0 mm. Duração, dois a três dias.

1) Caixa Postal $97,78400-000$ Diamantino, MT, Brasil. 
Segundo instar (Fig. 3). Cabeça: verde com marmorizações laterofrontais castanho-claras; peças bucais castanho-escuras. Corpo: scoli torácicos castanho-escuros, mais claros no terço basal; scolus A8 castanho-escuro, pouco mais claro na base, haste espiniforme eriçada de pequenos espinhos. Parte mediana de cada segmento de A 1-8 protuberante, com maior largura na área espiracular e gradativamente mais estreita até a área subdorsal onde funde-se com os scoli; tais projeções e também os scoli são de coloração citrina, enquanto o tegumento tem a coloração de fundo de um verde mais forte. Placa supranal triangular com scoli maiores, um no dorso e um em cada lateral, e chalazae esparsas na área anal. Pernas torácicas castanho-claras, as abdominais e as anais pouco mais escuras. Comprimento, 10,0 mm. Duração, três dias.

Terceiro ínstar (Fig. 4). Cabeça: verde-olivácea clara, com duas estreitas faixas verticais marrom-avermelhadas, uma na área subfrontal e a outra na lateral; frontoclípeo amarelado; peças bucais marrom-avermelhadas. Corpo: tegumento verde-oliváceo claro. Scoli protorácicos amarelados, curtos, bifurcados e com ramificações espiniformes. Scoli meso- e metatorácicos semelhantes, longos quanto aproximadamente a metade do corpo, marrom-avermelhados com as ramificações pouco mais escuras. Scoli abdominais e a porção basal do scolus A8, amarelados. Pernas abdominais creme, pilosas e com os escudos marrom-escuros. Espiráculos elipsoidais marrom-avermelhados. Comprimento, 15,0 $\mathrm{mm}$. Duração, quatro dias.

Quarto ínstar (Fig. 5). Cabeça: como no ínstar anterior mas com as faixas pretas e a fronte verde-escura. Corpo: protórax com uma série de espinhos a partir da área espiracular, sendo maiores os dorsais. Scoli meso- e metatorácicos verde-escuros com anelações pretas e a porção apical esbranquiçada. Scoli abdominais subespiraculares marrom-escuros, curtos, espiniformes com pequenas ramificações esverdeadas; scoli supraespiraculares e subdorsais pontiagudos com minúsculas ramificações marrom-avermelhadas na borda interna e bela coloração metálica (prata) na borda externa. Scolus A8 com tamanho aproximado da metade dos maiores torácicos, verde-escuro com marmorizações marrom-escuras e os espinhos amarelados. Placa supranal com três scoli iguais, marrom-avermelhados, laterais com rugosidade amarelada e brilho prateado; dorso com chalazae esbranquiçadas, brilhantes. Espinhos amarelados na área ventral de A 1-2. Cada segmento abdominal com duas faixas oblíquas protuberantes, amareladas, a mais larga é menos inclinada para a frente que a outra e ambas iniciam-se na área subespiracular, a mais estreita atinge a área supraespiracular e a outra avança até a subdorsal exatamente na base dos scoli. Pernas torácicas verdes com manchas marrom-escuras, as abdominais também verdes, com os escudos parcialmente vináceos e com os espinhos amarelados na parte superior e pretos com os espinhos também amarelados na porção inferior próximo às plantas, estas marrom-escuras. Tegumento verde oliváceo com a metade dorsal em T2-3 esbranquiçada; área periférica dos espiráculos de A1-8, vinácea. Espiráculos marrom-escuros. Comprimento, 30-37 mm. Duração, cinco dias.

Figs 1-10. Psigida walkeri, ovos, larvas e adultos. (1) Ovos; (2) larvas de primeiro instar, vista dorsal; (3) larvas de segundo instar, vista dorsal; (4) larvas de terceiro instar, vista lateral; (5) larva de quarto instar, vista laterodorsal; (6-7) larvas de quinto instar: (6) vista lateral, (7) vista laterodorsal; (8) pupas, vistas dorsal, ventral e lateral; (9-10) adultos, vista dorsal: (9) macho, (10) fêmea. 


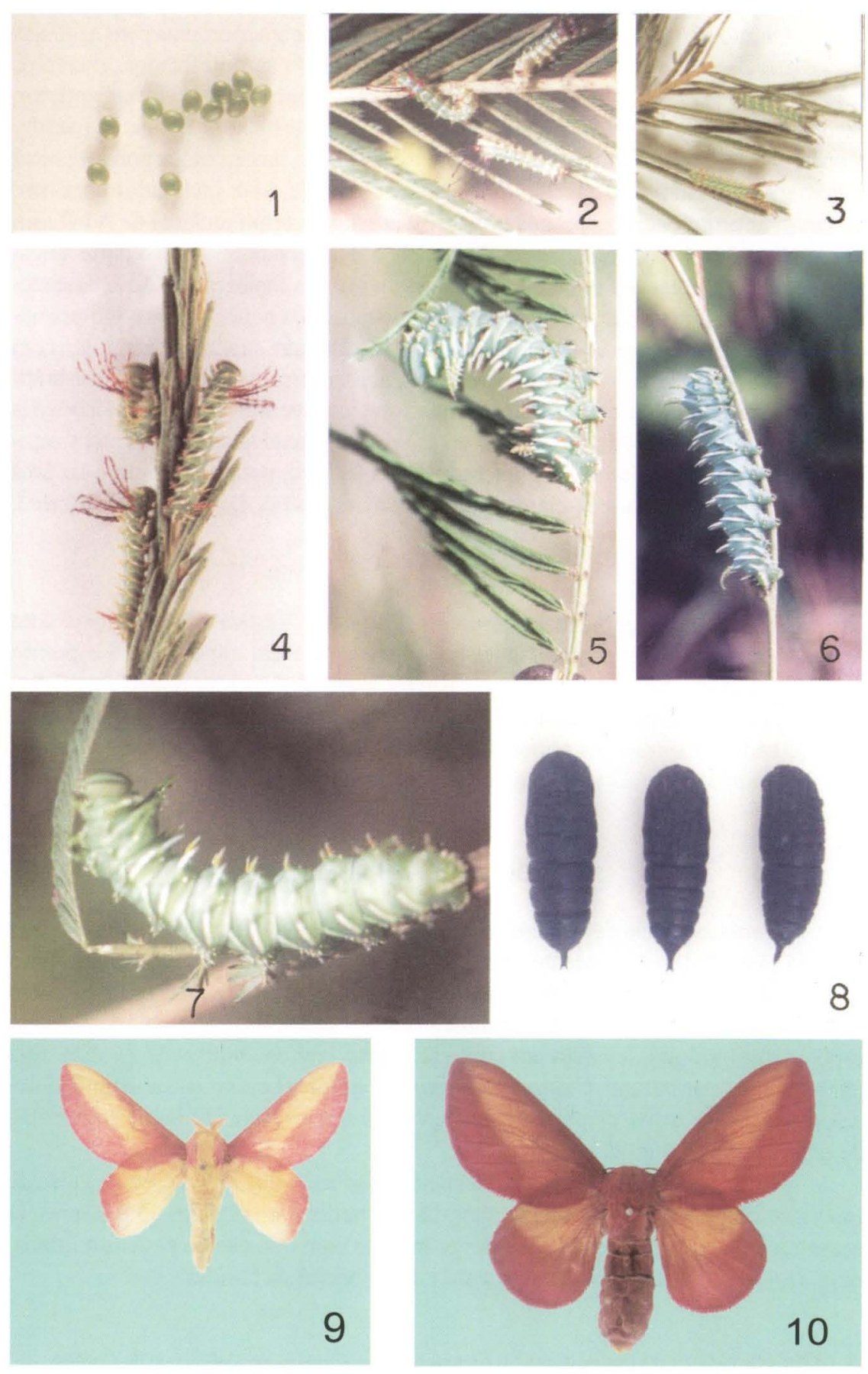


Quinto instar (Figs 6-7). Cabeça: como no ínstar anterior, mas com as faixas frontolaterais verde-escuras. Corpo: scoli protorácicos não ramificados, exceto os subespiraculares. Scoli meso- e metatorácicos mais curtos que no instar anterior, verde-oliváceos, brilhantes, com os espinhos pouco mais claros. Scolus A8 verdeoliváceo com leve tom marrom, espinhos amarelados, haste com a porção apical fortemente curvada para trás. Scoli subespiraculares de A1-8 inclinados para trás, castanho-avermelhados, espinhos oliváceos; scoli supraespiraculares de A1-9 sem as ramificações, lisos, borda externa prateada, a interna ocrácea com a parte apical esverdeada. As duas séries de scoli subdorsais são: os maiores em A1-7 assemeIham-se aos supraespiraculares; os menores, localizados pouco abaixo, são prateados na borda externa e esverdeados na interna. Escudo supranal triangular com verrugas dorsais e laterais esbranquiçadas. Espaços intersegmentais de A 1-6 esbranquiçados com leve tom violáceo. Pernas torácicas verdes com marmorizações castanho-escuras, as abdominais e as anais, verdes, escudos anegrados, com espinhos escuros e amarelados. Tegumento verde-oliváceo, pouco mais claro na área dorsal. Espiráculos marrom-claros, peritrema mais escuro. Comprimento, $40 \mathrm{~mm}$. Duração, cinco dias.

\section{Pupa (Fig. 8)}

Tegumento áspero, marrom-escuro brilhante. Vértice e adjacências com rugosidade fina; olhos parcialmente mais claros; antenas, clípeo, labro e pernas salientes. Estojo das asas granuloso, áspero, com as nervuras pouco aparentes. Metanoto com duas protuberâncias dorsais. Espaços intersegmentais lisos, marromavermelhados. Espiráculos elipsoidais, pouco mais claros. Cremaster bifurcado, preto. Comprimento, $23 \mathrm{~mm}$. Maior largura, $7 \mathrm{~mm}$; menor, $6 \mathrm{~mm}$. Diapausa, oito dias.

\section{DADOS BIONÔMICOS}

Com ocorrência na Venezuela, Colômbia, Bolívia, Paraguai e Brasil, Psigida walkeri (Figs 9-10) é freqüente na região do Alto Rio Arinos, Diamantino, Mato Grosso, Brasil, de onde procede o material estudado. Nessa região é encontrada em todos os meses chuvosos, janeiro-maio e setembro-dezembro, o que sugere ser uma espécie multivoltina, levando em conta seu curto ciclo evolutivo de 35 dias. Sua planta hospedeira natural, Calliandra parviflora Benth. (Leguminosae-Mimosoideae), essência arbustiva, de porte pequeno, vegeta no cerrado e nas bordas das matas de galeria em solos argilosos.

No solo, com secreções a larva une detritos em volta de seu corpo à guisa de um tosco casulo. A eclosão dos imagos dá-se a tarde, por volta das 15:00 horas. O acasalamento ocorre nas primeiras horas da noite com duração de poucos minutos, mais rápido que o habitual para a maioria das espécies da família.

AGRADECIMENTO. Ao Prof. Gert Hatschbach, do Museu Botânico Municipal de Curitiba, Paraná, pela identificação da planta hospedeira. 


\section{REFERÊNCIAS BIBLIOGRÁFICAS}

Lemaire, C. 1988. Les Saturniidae Américains. III. Ceratocampinae. San José, Museo Nacional de Costa Rica, 480p.

Oiticica-Filho, J. 1959. Tipos de Saturnioidea no United States National Museum. 16 - Gêneros Psilopygida Michner, 1949 e Psigida gênero novo. (Lepidoptera Adelocephalinae). Bol. Mus. Nac., n.s. Zoologia, 199: 1-33.

Recebido em 05.VIII.1999; aceito em 18.VIII.2000. 